\title{
Renomeando o fracasso escolar
}

\author{
Magda Pozzobon \\ Universidade do Vale do Rio dos Sinos - São Leopoldo - RS - Brasil \\ Fénita Mahendra \\ Universidade do Vale do Rio dos Sinos - São Leopoldo - RS - Brasil \\ Angela Helena Marin \\ Universidade do Vale do Rio dos Sinos - São Leopoldo - RS - Brasil
}

\begin{abstract}
Resumo
Teve-se como objetivo investigar o significado atribuído por alunos, pais e professores ao termo fracasso escolar e apontar outros que poderiam substituí-lo. Foi realizado um estudo exploratório e transversal de abordagem mista, do qual participaram 65 alunos, 66 pais e 58 professores da rede de ensino fundamental de São Leopoldo/RS, os quais responderam um breve questionário. Os resultados indicaram que a maioria dos alunos e pais responsabilizou o aluno pelas reprovações, enquanto os professores ressaltaram a multicausalidade do fenômeno (indivíduo, família, escola, sociedade). As expressões mais referidas pelos alunos para substituir o termo foram desinteresse, baixo desempenho escolar e dificuldade de aprendizagem. Pais e professores indicaram as expressões baixo desempenho escolar e negligência/descaso político e social com a educação. Os professores também sugeriram o termo desafios na educação, que inspira a ideia de transpor as dificuldades e não recai sobre um único sistema. Um número pouco expressivo de participantes considerou adequado o termo fracasso escolar.
\end{abstract}

Palavras-chave: Fracasso escolar; rendimento escolar; ensino fundamental.

\section{Renaming the school failure}

\begin{abstract}
The purpose of this article was to investigate the meaning attributed by students, parents and teachers to the term school failure and to point out others that could replace it. A cross - sectional exploratory and cross - sectional study was carried out, involving 65 students, 66 parents and 58 teachers from the São Leopoldo / RS primary school system, who answered a brief questionnaire. The results indicated that most of the students and parents blamed the student for the disapprovals, while the teachers emphasized the multicausality of the phenomenon (individual, family, school, society). The expressions most often referred to by students to replace the term were lack of interest, poor academic performance and learning difficulties. Parents and teachers indicated expressions of low school performance and neglect, neglect of politics and society with education. Teachers also suggested the term education challenges, which inspires the idea of overcoming difficulties and does not fall on a single system. A small number of participants considered the term school failure to be adequate.
\end{abstract}

Keywords: Academic failure; school performance; elementary school.

\section{Renombrando el fracaso escolar}

\section{Resumen}

En este estudio se tuvo como objetivo investigar el significado atribuido por alumnos, padres y profesores al término fracaso escolar y apuntar otros que podrían substituirlo. Se realizó un estudio exploratorio y transversal de abordaje mixto, del cual participaron 65 alumnos, 66 padres y 58 profesores de la red de enseñanza primaria de São Leopoldo/RS, los cuales respondieron un breve cuestionario. Los resultados indicaron que la mayor parte de los alumnos y padres responsabilizó el alumno por las reprobaciones, mientras que los profesores resaltaron a múltiples causas del fenómeno (individuo, familia, escuela, sociedad). Las expresiones más referidas por los alumnos para substituir el término fueron desinterés, bajo desempeño escolar y dificultad de aprendizaje. Padres y profesores indicaron las expresiones bajo desempeño escolar y negligencia/descaso político y social con la educación. Los profesores también sugirieron el término desafíos en la educación, que inspira la idea de transponer las dificultades y no recae sobre un único sistema. Un número poco expresivo de participantes consideró adecuado el término fracaso escolar.

Palabras clave: Fracaso escolar; rendimiento escolar; enseñanza primaria. 


\section{Introdução}

O termo fracasso escolar, utilizado para fazer referência às dificuldades de aprendizagem (Lima, 2014), problemas de comportamento (Osti \& Brenelli, 2013a; Osti \& Brenelli, 2013b), baixo desempenho escolar (Gauffin, Vinnerljung, Fridell, Hesse, \& Hjern, 2013; Guler, 2013; Kamtsios \& Karagiannopoulou, 2013; Odd, Evans, \& Emond, 2013; Soponaru, Tincu, \& Iorga, 2014; Williams, Dunlop, Kramer, Dever, Hogue, \& Jain, 2013), distorção idade-série/ano (Silva, 2014; Soares, 2015), abandono escolar precoce (Berg, Rostila, Saarela, \& Hjern., 2014; Soares, 2015) ou repetência (Ferrera, López, \& Rodríguez, 2014; Gran \& Nieto, 2013; Nocentini, Calamais, \& Menesini, 2012; Soares, Aranha, \& Antunes, 2013) é amplamente difundido no contexto nacional e internacional, sendo também usado pelo Conselho Nacional de Educação (Parecer CNE/CEB n. 11/2010,2010). Embora fique evidente na literatura a ambivalência e a falta de especificidade do conceito, ele ainda é utilizado como um termo atual e considerado mais sintético que outras expressões utilizadas com a mesma conotação, o que talvez dificulte sua substituição (Marchesi \& Pérez, 2004).

No entanto, o uso desse termo tem sido questionado, uma vez que pode trazer conotações pejorativas aos alunos, causando prejuízos sobre seu desempenho acadêmico e social ao longo da vida (Kelly \& Pink, 1982). Estudos recentes ainda revelam o predomínio da tendência à culpabilização dos alunos (Guler, 2013; Hjörne \& Säljö, 2014; Osti \& Brenelli, 2013a; Osti \& Brenelli, 2013b; Pezzi, Marin, \& Donelli, 2016; Pezzi \& Marin, 2016) e/ou suas famílias pelo baixo desempenho acadêmico ou reprovação escolar (Bastos, Fernandes, \& Passos, 2009; Pezzi \& cols., 2016).

Tal dado reforça um perfil de fracasso, o qual pode abalar a autoestima e a autoconfiança do aluno rotulado (Millones, Leeuwen, \& Ghesquière, 2013; Pezzi \& cols, 2016), com conseqüente impacto na diminuição da motivação para estudar (Costa, Lima, \& Pinheiro, 2010; Martinelli \& Genari, 2009), além de outras intercorrências clínicas graves, tais como o uso de tabaco (Gran \& Nieto, 2013), abuso de álcool e de outras drogas (Gauffin \& cols., 2013; Gran \& Nieto, 2013), bem como comportamentos disfuncionais, levando ao risco de gravidez na adolescência, marginalização e criminalidade (Rumberger, 2011).

Já em 1998, Delors chamava a atenção à possibilidade de o termo fracasso escolar conduzir à exclusão social, uma vez que abala moralmente o indivíduo a quem o termo é atribuído. De forma semelhante, Ferraro (2004) destacou a associação desse termo com indicativos de exclusão escolar e social, frisando que a escola tem se orientado equivocadamente através de uma ótica da progressão versus exclusão, sem considerar as individualidades. Outros autores também sinalizam que a utilização do termo está a serviço da manutenção da desigualdade social, na qual a escola se posiciona como transmissora de conhecimentos, assegurando a submissão às ideologias dominantes, retirando de si a responsabilidade do fracasso e repassando ao sujeito a condição de fracassado e excluído (Lagana-Riordan \& cols., 2011; Madalóz, Scalabrin, \& Jappe, 2012). No entanto, qualquer pessoa que se dispõe a aprender corre o risco de fracassar em algum momento ou por algum tempo, o que não significa a impossibilidade de mudança (Ireland \& cols., 2007). Nesse sentido, Esteban (2009) propõe a valorização das múltiplas aprendizagens e das diferentes experiências escolares, bem como a importância de a escola e os professores reconhecerem a realidade dos alunos, favorecendo o direito às diferenças e singularidades e evitando rótulos e marginalizações.

Assim, faz-se necessário considerar não somente os aspectos cognitivos, mas também os afetivos e sociais que estão envolvidos no processo de construção do saber, além de outras variáveis intra e extra-escolares, ampliando o olhar não somente sobre o fenômeno chamado fracasso escolar, que é multifacetado (Osti \& Brenelli, 2013a; Osti \& Brenelli, 2013b; Patto, 2007), mas também sobre esse termo, uma vez que ele não é a expressão da incapacidade de aprender, mas da insuficiência de novos modelos necessários no processo de ensino-aprendizagem (Patto, 2007; Esteban, 2009), bem como de políticas públicas mais atentas às demandas educacionais da população (UNESCO, 2014).

Apesar do questionamento sobre o termo fracasso escolar não ser recente, nenhum estudo de abordagem empírica que tenha tido como objetivo modificá-lo foi encontrado. Desta forma, com o intuito de investigar o significado atribuído ao referido termo e apontar outros que poderiam substituí-lo, foi realizado um levantamento junto a alunos, familiares e professores da rede de ensino fundamental do município de São Leopoldo/RS. A motivação para a realização desse estudo foi buscar compreender se o termo fracasso escolar continua sendo considerado o mais adequado para quem está diretamente inserido no processo de ensino-aprendizagem ou se novas possibilidades podem surgir para expressar este fenômeno que é ainda muito presente, atual e relevante no Brasil (INEP, 2012).

\section{Método}

\section{Participantes}

Participaram desta pesquisa 65 alunos adolescentes matriculados nos últimos anos do ensino fundamental, 66 pais e 58 professores de duas escolas da rede de ensino do município de São Leopoldo/RS. As escolas selecionadas haviam pedido auxílio para a Supervisão Pedagógica da Secretaria Municipal de Educação (Pedagógico/SMED), devido às sucessivas reprovações de seus alunos. Já a seleção da amostra foi feita por conveniência.

\section{Delineamento e procedimentos}

Trata-se de um estudo exploratório e transversal de caráter misto. Inicialmente, foi feito contato com a Secretaria 
Municipal de Educação de São Leopoldo/RS para apresentar a proposta do estudo maior, do qual este constitui um recorte, e obter a autorização para a sua realização. Uma vez que a autorização foi concedida, e com a devida avaliação e aprovação do Comitê de Ética em Pesquisa da UNISINOS (Projeto $\left.N^{\circ} 12 / 084\right)^{1}$, planejou-se a realização da coleta de dados.

Duas escolas municipais foram contatadas para apresentação da pesquisa e, a partir do aceite em participar, foram realizados os convites aos alunos e professores em sala de aula, e aos pais em reuniões pedagógicas e de entrega de avaliações. Àqueles que se interessavam foi entregue o Termo de Consentimento Livre e Esclarecido - TCLE (pais e professores)e o Termo de Assentimento (alunos) e solicitado o preenchimento de um breve questionário que continha as seguintes perguntas abertas:"O que é fracasso escolar para você? e "Se tivéssemos que usar outro termo que signifique a mesma coisa que fracasso escolar, qual seria?".

Os questionários foram examinados por meio da análise temática (Braun \& Clarke, 2006), que preconiza os seguintes passos: 1) transcrição, leitura e releitura de dados; 2) codificação do material; 3) identificação dos temas; 4) análise das inclusões realizadas em cada tema quanto a sua definição; e 6) análise final. A codificação do material, assim como a identificação dos temas foi realizada por dois juízes, tendo havido $98 \%$ de concordância entre eles em relação às respostas dos alunos, 92\% entre as respostas dos pais e $88 \%$ referente às respostas dos professores ${ }^{2}$. Os questionários foram analisados considerando dois temas, definidos a priori: 1) Significado do termo fracasso escolar; e 2) Expressões que poderiam substituir o termo fracasso escolar, os quais são apresentados abaixo.

\section{Resultados}

\section{Significado do termo fracasso escolar}

A leitura e análise dos questionários preenchidos pelos participantes deste estudo deram origem a quatro categorias temáticas, conforme os significados atribuídos pelos participantes ao termo fracasso escolar e aos fatores apontados como associados a este fenômeno. As categorias temáticas são: 1) Responsabilização do aluno; 2) Responsabilização do aluno e sua família; 3) Responsabilização do aluno, sua família e sistema escolar; e 4) Fenômeno social amplo, pelo qual são responsáveis aluno, família, escola, sociedade e políticas públicas. As categorias são apresentadas a seguir, ilustradas por meio de recortes das respostas dadas pelos participantes.

1 O presente estudo faz parte de um projeto maior, cujo título é "Fracasso escolar: sintoma e/ou reatividade ao sistema de ensino?", coordenado pela Prof ${ }^{a}$. Dra . Angela Helena Marin e financiado pelo CNPq.

2 De acordo com Robson (1995), os valores do Coeficiente Kappa são assim classificados: suficientes $(0,40$ a 0,60$)$, bons $(0,60$ a 0,75$)$ e excelentes (acima de 0,75).

\section{Responsabilização do aluno}

A grande maioria dos alunos entrevistados (92,3\%) responsabilizou a si próprio pelo fracasso escolar, relacionando-o a fatores como: não prestar atenção nas aulas, não atingir conceitos satisfatórios, não conseguir entender a matéria, reprovar mesmo estudandoe desistir/evadir da escola. Tais fatores foram associados ao desinteresse, que os impossibilita de ir adiante, mesmo tendo capacidade, pois estão indiretamente relacionados a "muitos problemas em casa ouna rua"(A26) ${ }^{3}$. Também indicaram que o fracasso escolar está intimamente relacionado à motivação e é "algo vinculado à autoestima no processo de aprendizagem, algo que inviabiliza a capacidade de um ou mais indivíduos de aprender" (A5), pois "quando não temos sucesso nas aulas, a nossa autoestima fica lá embaixo e não temos mais vontade de estudar e rodamos" (A35). Inclusive, a palavra derrota foi associada ao termo fracasso, "porque fracassar é a mesma coisa que ser derrotado" (A35).

Nesse sentido, o medo do fracasso escolar, que se revela um estigma que adere ao alunocomo um rótulo, aparece em mais de um relato, pois muitos deles reconhecem que "fracasso escolar é uma palavra que todos os alunos têm medo de ser chamados, já por causa do pronunciamento. Se fossem chamadas de dificuldades na escola as pessoas não iam ficar tão inseguras dessa palavra" (A4). A aderência do termo é tamanha que pode atingir um grau de personalização, deixando de ser um fenômeno: "fracasso escolar é uma pessoa que não quer saber de nada" (A8); "é alguém que teve oportunidade, mas mesmo assim não quis estudar" (A10).

Alguns alunos expressaram sua contrariedade quanto ao uso do termo fracasso escolar, pois o associaram à reprovação e acreditam que reprovação não é sinônimo de fracasso, poisobservaran que "muitos reprovam por dificuldades no aprendizado" (A26, 64, 65), e deveriam ser ajudados e não excluídos ou estigmatizados, uma vez que consideram queestudar pode proporcionar uma vida digna e com melhores oportunidades de escolhas sociais e profissionais, "pois os estudos são a base para a gente ter uma vida boa" (A64) e, além de repetir o ano, a pessoa "para de ter amigos" (A57). Consideraram que o fracasso seria somente a desistência total e o abandono da escola ou "quando a pessoa é muito burra e repete muitas vezes o mesmo ano" (A28). Nesse sentido, expressões como "incompetência" (A31, 41, $42,44)$ e "burrice" (A28, 46, 57, 60, 61, 64) apareceram nas respostas dos alunos, sinalizando reflexos na autoestima dos mesmos, ao ponto de "a pessoa se sentir fracassada em tudo o que faz, na escola e em qualquer lugar,pois elafracassou em sua vida!" (A33), e isto "quer dizer uma coisa decepcionante, tipo eu perdi, eu fracassei" (A7).

Os relatos nos revelam que, ao sentir-se enquadrado no conceito de fracasso escolar, o aluno se desmotiva a pros-

3 A letra e o número entre parênteses identificam a que grupo pertence o participante que forneceu a resposta e a ordem em que foi acessado. As letras $A$ se referem a respostas de alunos, $F$ de familiares e $P$ de professores. 
seguir e acaba visualizando um futuro com menores chances de inserção social. Abandonando a escola, ele "fica na rua fazendo o que não deve" (A51)e, desta forma, "não chega onde queria chegar" (A20), perde o foco nos estudos e como consequência corre o risco de marginalizar-se e "viver no mundo das drogas e da violência" (A25), sem conseguir um bom emprego no futuro, tornando-se assim, "um Zé Ninguém" (A55). Por fim, os adolescentes também mencionaram que o termo fracasso escolar não está somente associado às notas e desempenho, mas ao comportamento do aluno como um todo. Quanto maior a aderência que o aluno tiver ao termo fracasso escolar, menor tende a ser seu comprometimento com os estudos, com a construção de um futuro melhor e aumentarão as chances dele manisfestar comportamentos inadequados, incluindo desrespeito a colegas, professores e ambiente escolar, pois "o fracasso escolar pode gerar conflitos casuais, como brigas e discussões desnecessárias" (A21). Isto tudo é reconhecido como um problema para eles, pois "perder um ano de escola pode prejudicar não apenas na escola, mas também na vida pessoal" (A1).

Os pais, por sua vez, de igual forma, responsabilizaram, em sua maioria, os alunospelo desempenho escolar (53,8\%): "fracasso escolar não existe, existe sim é falta de interesse dos alunos, pois os profissionais estão aí para dar educação e ensino aos nossos filhos, só não aprende quem não quer" (F18). No seu entendimento, o fracasso escolar ocorre quando os alunos "desrespeitam o professor, não fazem as tarefas e trabalhos, faltam às aulas, levam tudo numa brincadeira, não se dedicam, nem se esforçam" (F15), "não se empenham" (F24), "não se interessam e não colaboram" (F23). A falta de atenção, interesse, colaboração e empenho, bem como a conversa excessiva em sala de aula, também foram apontadas pelos pais como causadoras do baixo desempenho escolar e consequente reprovação, fazendo com que o aluno seja percebido como uma decepção "acho que decepção seria a palavra certa (F19)". Eles associam o termo fracasso escolaràs palavras "derrota" (F20, 64) e"decepção" (F6, 19)e entendem que é possível que haja também algum problema psicológico ou neurológico com o filho, pois se há problemas no desempenho escolar, o aluno tem dificuldades, "é fraco" (F50), "tem hiperatividade neurológica" (F53) e "tem fraqueza de memória,tem que levar para uma consulta" (F52). Alguns também acreditam que o termo fracasso escolar está adequado se associado aos alunos que não se empenham nos estudos "quando o aluno não se empenha nos estudos, acho que fracasso escolar já diz tudo" (F24).

Por outro lado, os pais consideram o termo fracasso escolar muito pesado e inadequado para as diversas situações vivenciadas pelos alunos e suas famílias. Percebem que os filhos podem ter diferentes tipos de dificuldades para aprender, assimilar conhecimentos e até problemas de comportamento, que influenciam o desempenho escolar, mas acreditam que o termo fracasso escolar somente poderia ser atribuído a "uma pessoa que simplesmente desiste de tudo sem ter ao menos tentado" (F45). Entendem que este não é o caso da maioria dos alunos que possuem dificuldades, pois os pais relataram sua preocupação em ajudar os filhos no processo de aprendizagem, mesmo não tendo, muitas vezes, nível de escolaridade. Relataram também a sensação de tristeza e fracasso que recai sobre os pais, pois sentem que passam "anos de sua vida lutando pelo filho" (F14), que nem sempre atinge os objetivos que a escola determina e, a cada final de ano,temem a possibilidade de escutar novamente "pois é, mãe, não deu, teu filho não quer saber de nada!" (F14). No entanto, sentem que, embora desconheçam a melhor maneira de ajudar seus filhos, seguem "sempre junto dele, conversando, explicando, implorando." (F14). Alguns pais acreditam que o termo "fracasso escolar seria um nome certo para as coisas erradas da escola" (F36).

Parte dos professores entrevistados $(22,4 \%)$ também acredita que o fracasso escolar está relacionado ao aluno e ocorre quando este "não atinge as metas e/ou objetivos traçados pelos professores e/ou escola" (P10, 15, 24, 29, $31,39,57)$ ou quando são tentados "todos os métodos pedagógicos para que o aluno tenha um bom desenvolvimento escolar e o mesmo chega ao final do ensino fundamental com dificuldades" (P25). Especificamente para um dos professores, fracasso escolar "é ter um aluno no nono ano que não consegue interpretar um texto simples ou quando um adolescente escreve em sua redação expressões como: agente fumo, tipo assim, o cara..." (P23).

\section{Responsabilização do aluno e sua família}

Entre os alunos participantes, nenhum deles apontou a família como responsável direta ou indiretamente por seu desempenho escolar e apenas $7,6 \%$ dos pais entendia que a família poderia influenciar o desempenho escolar dos filhos. Para estes pais, a ausência da família seria responsável pela desmotivação do filho para estudar e o fracasso escolar "é não ter apoio dos pais" (F7), pois muitas vezes "o aluno não se empenhou, mas os pais não exigiram" (F6) e "a ausência da família desestimula os alunos em aprender" (F4).

Alguns pais admitiram ter dificuldades importantes em relação à educação dos filhos. Percebem a importância da participação da família na escola e acreditam que estão em falta com os filhos neste sentido. Sinalizam que gostariam que houvesse mais orientação e auxílio, talvez um grupo de "amigos da escola e orientadores" (F1), para ajudar os pais a compreenderem as questões que envolvem o processo de ensino-aprendizagem. Eles acreditam que não haveria fracasso escolar se houvesse "alguém para nos orientar sobre algo que os filhos estão precisando" (F1). Pontua-se a necessidade de a escola estar preparada para acolher essa demanda, visando compreender que "todos precisamos de ajuda quando estamos com problemas que, nós pais, não conseguimos resolver com nossos filhos" (F1).

Em relação a este tema, apenas alguns professores $(10,3 \%)$ pontuaram que a participação dos pais nos estudos e na educação dos filhos interfere no desempenho escolar. Contudo, acreditam que os alunos não conseguem atingir os objetivos e as metas por desinteresse nos estudos, o qual 
tem origem no seio familiar, pois os pais têm dificuldades em colocar regras e limites e exercer seu papel na educação, o que sobrecarrega o educador. Assinalam, também, que muitos pais têm dificuldades na educação dos filhos e"não colocam regras em nada, os filhos mandam neles e a família está ausente de tudo" (P5). Acrescentam que muitas famílias são desestruturadas social e economicamente e possuem um padrão de comportamento evitativo em relação ao acompanhamento da vida escolar dos filhos, o que dificulta a comunicação entre o sistema escolar e familiar: "o fracasso escolar reitera-se pela falta de motivação da família na construção mútua da aprendizagem do aluno" (P26).

Para esses professores, a família deveria ser "a primeira responsável pela aprendizagem, ajudando nos deveres de casa, acompanhando todo o processo de educação, dando estímulo e também mantendo contato com os professores"(P43), mas geralmente "não está presente na vida dos filhos" (P3), pois "tentamos chamar a família para participar e a mesma não aceita, se recusa" (P11), "pensam que a escola é responsável pela sua educação” (P26). Relatam que muitas das situções vividas na escola são ignoradas pela família, que também não dá continuidade aos trabalhos desenvolvidos com os alunos em sala de aula da mesma forma que não os estimulam a superar obstáculos. Acreditam que se a família transmitisse aos filhos valores que priorizassem a educação seria possível um ambiente escolar de melhor qualidade, pois "o exemplo e os valores de ética e respeito passados pela família são fundamentais para a formação do ser humano" (P54) e, além disto, "a falta de apoio e atenção da família agrava mais ainda a situação” (P31).

\section{Responsabilização do aluno, sua família e sistema escolar}

Quanto a esta categoria, apenas um dos alunos referiu que a escola "é meio ruim e ninguém leva a sério" (A36), sugerindo que a instituição escolar tem parcela de responsabilidade pelas dificuldades vividas pelos alunos nesse contexto. Já alguns pais $(10,8 \%)$ entenderam que o fracasso escolar envolvia "um conjunto de negligências feitas pelo aluno, pais e professores" (F11). Pontuaram que fracasso "é o resultado de muitas falhas na educação: alunos são descomprometidos, há desinteresse dos pais e os professores desmotivados e cansados" (F10). Para esses pais, os três sistemas são interdependentes e se um deles "não dá a devida assistência, prejudica o todo" (F8). Além disso, destacaram que "se não caminharmos juntos na educação e aprendizado, ocorre o fracasso escolar e aí todos nós falhamos" (F11). E, nesse caso, concordam com o uso do termo fracasso escolar, pois "fracasso escolar fala tudo: envolve aluno, família, professores, colegas... outra palavra para mim seria tristeza, tristeza..." (F3).

Parte dos professores $(31,1 \%)$ concordou com os pais referindo que somente juntos os três sistemas podem fazer diferença na educação, mudando não só o termo fracasso escolar, mas a realidade escolar de sucessivas reprovações e suas consequências sociais. Mencionaram que por se sentirem mal pagos e pouco reconhecidos como classe, existe grande desmotivação dos professores para a realização de um trabalho eficiente que modifique o quadro de desinteresse dos alunos. Esses sentimentos são percebidos pelos pais, que sinalizaram que algumas aulas acabam sendo dadas por "pessoas que não se interessam em dar aulas, só pensam em si e têm pouca vontade” (F2).

Os professores também destacaram a ineficácia da escola em desempenhar o seu papel e o desinteresse da classe profissional, pois

as tecnologias estão aí, os professores devem capacitar-se e adequarem-se ao perfil do aluno que 'não rende' como os demais, pois cada comunidade pede um planejamento diferente. Há professores que desistem de aplicar novas estratégias para que o fracasso escolar diminua. Só juntos, escola, professores e alunos, podemos mudar esta triste realidade" (P32).

Alguns professores pensam que o termo fracasso escolar é muito forte e que para o aluno é muito pesado, "mas resume tudo" (P42) sendo o resultado de vários fatores, tais como "pais, alunos, professores e equipe diretiva... todos em algum momento falham e proporcionam o fracasso" (P42). Também acreditam que "este é o termo que deve ficar, porque não deixa de ser um fracasso para todos os envolvidos" (P40), acham que não existe outro termo para ser "o substituto para uma classificação escolar tão injusta, visto a ineficácia da escola atual em desempenhar seu papel' (P24) e sentiram dificuldade em encontrar outra alternativa para o termo: "não consigo pensar em outra expressão para designar o termo, pois de fato penso que a escola é uma instituição falida" (P23). Por fim, alguns professores conceituaram fracasso escolar, contrapondo-o ao sucesso escolar: "entendo sucesso escolar como sendo o real aprendizado por parte do aluno, através de uma metodologia dinâmica e criativa, pela presença e participação dos pais na educação dos filhos e o envolvimento da equipe pedagógica no processo de ensino-aprendizagem dos alunos" (P44). "Fenômeno social amplo, pelo qual são responsáveis aluno, família, escola, sociedade e políticas públicas".

Apenas um aluno revelou um olhar mais global sobre o tema, indicando que "fracasso escolar são as milhares de crianças e adolescentes que param de estudar por qualquer motivo. As meninas, às vezes, ficam grávidas precocemente ou precisam trabalhar, e os meninos também. Tudo isso prejudica muito o aprendizado e o futuro das pessoas. Isto é falta de cultura e de direitos!" (A27). Já os pais $(16,9 \%)$ acreditavam que a falta de professores, sua insuficiente qualificação e remuneração, a falta de merenda, de material escolar, de cadeiras e de toda a infraestrutura necessária propiciam o fracasso escolar, pois para eles "onde tem estrutura e bons salários se ensina com prazer" (F32). Alguns pais responabilizam os governos municipal, estadual e federal por não investirem na educação, na proteção do cidadão e não desenvolverem projetos que possam beneficiar mais 
os jovens, uma vez que "o governo só quer tirar vantagens dos alunos e dos pais" (F2). Para eles, não é o aluno, mas a educação que está fracassada há muitos anos, sinalizando que "temos que investir mais na educação para não superlotar no futuro os presídios" (F55).

Para a grande maioria dos professores $(60,3 \%)$ "o termo deve nos remeter a um olhar mais amplo, considerando vários fatores responsáveis pelo fracasso escolar, como estrutura escolar macro e micro, o sistema em geral, a família, a proposta pedagógica" (P51). Nesta mesma direção, apontaram as diversas dificuldades que enfrentam como um modelo pedagógico ultrapassado que resulta em uma escola conteudista e uma má administração do trabalho de equipe.

Nesse sentido, se referiram ao fracasso escolar como sendo "fruto de uma sociedade que não valoriza a educação" (P56) e que ele é também um fracasso social e "representa o fracasso do sistema de ensino" (P36, 38), representando "um fracasso para todos os envolvidos" (P40). Dessa forma, a escola se reflete como "uma instituição falida" (P23) que não recebe apoio do poder público, tais como melhores salários para os professores e profissionais necessários para o apoio aos docentes e discentes, tais como psicólogos, pedagogos, psicopedagogos e orientadores educacionais, carecendo especialmente dos serviços de "psicologia, orientação educacional e reforço escolar" (P49). Ainda ressaltaram que muitos esperam que os professores, além de terem que ensinar os conteúdos programáticos referentes à educação pedagógica, possuem "a obrigação de educar estas crianças como se fossemos a célula familiar, suprindo as necessidades e os compromissos que, na maioria das vezes, os pais e os familiares não atendem" (P58).

Por fim, os professores destacaram que o termo fracasso escolar não respeita os alunos, pois nem todos aprendem da mesma forma. Faz-se necessário, portanto, repensar o modo de ensinar, considerando que cada comunidade apresenta um perfil diferente, características e demandas específicas e exige do professor certa adequação, para que se sinta "preparado para os tipos de educando que estamos em foco" (P48). Pontuaram que deve-se dizer: "Chega de rótulos! Quem rotula o aluno não é só o professor, mas a sociedade em geral. Nivelar alunos é simplesmente impossível, é mascarar uma verdade. A avaliação deve ser individual, sem comparações ou padronização." (P47).

\section{Expressões que poderiam substituir o termo fracasso escolar}

Este tema se refere aos termos sugeridos pelos participantes como possíveis substitutos do fracasso escolar. A Tabela 1 apresenta os termos mais referidos e a percentagem em que apareceram nas respostas dos participantes.

Observou-se, por meio da análise das respostas dos participantes, que apenas uma pequena parcela dos 189 entrevistados $(5,8 \%)$ concordou com a adequação e manutenção do termo fracasso escolar. A grande maioria $(68,2 \%)$ procurou encontrar outra expressão para substituir o termo, expressando rejeição e desejo de modificá-lo. Alguns pontuaram que é um termo muito pesado, especialmente porque recai sobre os alunos. Ao mesmo tempo, pode-se perceber a dificuldade em encontrar uma palavra ou expressão que melhor pudesse representar o que o termo propõe, principalmente pelo seu caráter ambivalente e multifacetado.

Pais e professores utilizaram termos que indicaram seu sentimento de tristeza diante da percepção de negligência e descaso com a educação, enquanto os alunos preferiram palavras como "desinteresse", e "baixo desempenho escolar". Nas entrevistas, não houve referência ao significado exato da palavra desinteresse e não ficou explícito se a fonte do desinteresse seria somente do aluno ou se referia também a outros sistemas. Quando os pais e professores utilizaram a palavra desinteresse, ela esteve mais vezes associada às políticas públicas, ao sistema de ensino ou à sociedade como um todo.

Tabela 1. Termos Propostos para Substituir Fracasso Escolar.

\begin{tabular}{lccc}
\hline Termos & Alunos (\%) & Pais (\%) & Professores (\%) \\
\hline Desinteresse escolar & 32,30 & 12,12 & 1,61 \\
Desempenho escolar & 10,76 & 15,15 & 4,17 \\
Dificuldades de aprendizagem & 10,76 & 4,54 & 27,58 \\
Negligência/descaso com a educação & - & 19,69 & 13,79 \\
Desafios na educação & - & - & 10,34 \\
Insucesso escolar & - & 3,57 & 3,44 \\
Fracasso escolar & 3,07 & & \\
\hline
\end{tabular}


Não foi possível verificar um consenso entre os três grupos entrevistados que apontasse um termo substituto para fracasso escolar, os termos propostos apresentaram grande variação e, inclusive, $25,9 \%$ dos participantes fugiu do assunto ou teve muita dificuldade de escolher um termo, preferindo não indicar nenhum. Um professor lembrou que esta questão é muito importante, mas apenas "mudar de nome não resolve o problema", pois é um tema muito sério e trata-se do não crescimento dos alunos "na área do conhecimento, dos relacionamentos e de sua evolução como cidadão!" (P13). Neste sentido, um dos termos que se destacou no grupo dos professores foi "desafios na educação", com significativa justificativa, pois as professoras acreditam que a trajetória escolar interrompida e justificada por tantos fatores intra e extraescolares conduzem ao abandono de sonhos e à falta de opções futuras de muitos jovens e, considerando que estes são os maiores prejudicados, com certeza, essa questão se coloca como um dos grandes desafios que se apresenta a todos os envolvidos no processo de ensino-aprendizagem.

\section{Discussão}

Através das respostas dos participantes, especialmente dos alunos, pode-se verificar que para grande parte deles o significado do termo fracasso escolar está relacionado a palavras que envolvem os sentimentos de frustração, rejeição e desvalia. Ficou evidente a associação deste termo às palavras "burrice", "desgosto" e "decepção", concordando com o que aponta a literatura quanto ao sentimento de culpa e responsabilização do aluno pelo fracasso escolar (Guler, 2013; Hjörne \& Säljö, 2014; Osti \& Brenelli, 2013b; Pezzi \& Marin, 2016). Os depoimentos também ratificam pesquisas anteriores sobre a maneira como o termo fracasso escolar abala a autoestima do aluno, sua autoconfiança e motivação (Millones \& cols., 2013; Pezzi \& cols., 2016). Os alunos descreveram medos e inseguranças relacionados à possibilidade de serem enquadrados no grupo de fracasso escolar como se fosse um rótulo pernicioso com grande poder de aderência, podendo conduzi-los ao desprazer de estudar (Costa \& cols., 2010; Martinelli \& Genari, 2009), bem como desmotivá-los para mudanças e crescimento.

Os alunos também referiram a tendência ao uso de drogas por parte daqueles que acabam se enquadrando no perfil de fracasso escolar, corroborando pesquisas anteriores (Gauffin \& cols., 2013; Gran \& Nieto, 2013). Relataram, ainda, que observam comportamentos disfuncionais de colegas, demonstrando que conhecem os riscos de marginalização e criminalidade. Os pais, de forma semelhante, manifestaram a sua preocupação com a melhora da educação como um todo para evitar a marginalização e a criminalidade, que podem ser consequências das sucessivas reprovações escolares. O risco de gravidez na adolescência também foi apontado, confirmando o que sinalizou Rumberger (2011).

Muitos professores reconheceram a multifatorialidade do fenômeno fracasso escolar, ainda que tenham respon- sabilizado, muitas vezes, o aluno e sua família, apontando o desinteresse e a falta de motivação e atenção dos alunos (Bastos \& cols., 2009; Guler, 2013; Hjörne \& Säljö, 2014; Pezzi \& cols., 2016), assim como a negligência, a omissão e dificuldades na educação dos filhos, conforme apontaram Bastos e cols. (2009) e Pezzi e cols. (2016).

Constatou-se ambivalência, mesmo por parte dos profissionais da educação, quanto ao significado do termo fracasso escolar, que é utilizado para referir vários fenômenos, como recentemente indicaram Pezzi e cols. (2016). Tal questão se refletiu na dificuldade de escolher um termo possível de substituir fracasso escolar, que hora foi associado exclusivamente ao aluno, ora às famílias, ora a outros sistemas. Embora a literatura venha associando o termo à defasagem idade e série/ano, por exemplo, apenas seis alunos, um pai e nenhum professor participante sugeriram esta associação. Deste modo, há uma defasagem também entre o que aponta a literatura e o que é concebido ou conhecido no ambiente escolar como sendo fracasso escolar. Esse aspecto pode permitir inferências sobre o distanciamento que existe entre a pesquisa, a formação profissional e as informações ou conhecimentos que chegam até a escola, sinalizando a necessidade de atualização dos profissionais envolvidos no processo de ensino-aprendizagem.

De forma semelhante, os dados também corroboraram as afirmações de Esteban (2009) quando os professores sugerem que as avaliações devem ter um caráter mais particular, atendendo às necessidades de cada aluno, pois a escola deve tornar-se um lugar que respeite as singularidades e não um local de julgamentos ou discriminação. Vários professores pontuaram a urgência de fazer adequações curriculares que valorizem as diferenças entre os alunos e a comunidade que dizem respeito a um possível esgotamento da classe profissional, que impede a motivação na busca de novas estratégias para estimular o índice de aproveitamento dos alunos.

Nesse sentido, foi sinalizada por pais e professores a importância do papel dos educadores no processo de ensino-aprendizagem, revelando que maior atenção do professor às diversidades dos alunos e a adequação dos métodos de ensino e de avaliação, que podem fazer muita diferença, conforme já apontaram Pezzi e Marin (2016). Alguns pais ainda lembraram que escolas melhores, com professores melhor qualificados, remunerados e satisfeitos e com uma proposta pedagógica adequada às necessidades dos alunos, podem aumentar as chances de sucesso escolar, o que já foi apontado por vários autores, que inclusive indicaram que o termo fracasso escolar pode estar à serviço de ideologias dominantes, que preferem responsabilizar o sujeito pelo seu fracasso e sua condição de excluído (Lagana-Riordan \& cols., 2011; Madalóz \& cols., 2012; Patto, 2007).

Diante da complexidade do tema, embora tenha havido um alto índice de rejeição ao termo fracasso escolar, percebeu-se uma grande dificuldade de renomeá-lo, havendo baixa homogeneidade entre as opções escolhidas. Renomear o fracasso escolar, encontrar um termo que o substitua e que contenha em si todas as dimensões a que ele se refere 
é tarefa difícil, como já apontaram Marchesi e Pérez (2004), mas nem por isso impossível. Alguns professores sugeriram o termo "desafios da educação", o qual mais se aproximou dessa ideia de complexidade, de desafiar a todos os envolvidos no processo de ensino-aprendizagem a construir novas possibilidades na educação. Além disso, este o termo não contém um sentido pejorativo, pelo contrário, transforma-se em um convite à criatividade e a novas ações. Assim, quer-se convidar a todos a aceitarem os "desafios na educação" e a buscarem meios de enfrentá-los!

\section{Considerações Finais}

O termo fracasso escolar é utilizado há muitos anos e foi incorporado como representante das situações de baixo desempenho escolar, dificuldades de aprendizagem e/ou comportamentais, reprovações, defasagem ano/série/idade e evasão escolar. De modo geral, no presente estudo, os alunos participantes entenderam que este termo é utilizado para responsabilizá-los pelo seu desempenho escolar, associando-o às palavras "desinteresse", "incompetência" e "burrice", sinalizando importante influência sobre sua autopercepção, autoestima e motivação. Da mesma forma, o termo responsabiliza outros sistemas, como a família e a escola, que, ao sentirem-se culpabilizados, desanimam diante de novos desafios. Assim, foi ratificada a necessidade de substituição do termo fracasso escolar por um termo que remeta menos à não-aceitação das singularidades, segregação, exclusão, culpabilização e suas consequências futuras, como falta de oportunidades profissionais e sociais aos alunos.

A reprovação escolar não pode significar um fracasso e, para tanto, é necessário que as escolas, assim como a sociedade, deixem de rotular os alunos. Para isso é necessário um termo que remeta ao trabalho de equipe envolvido e indispensável no processo de ensino-aprendizagem, no qual alunos, pais, professores, escolas e políticas públicas se tornem mais adequados, trabalhando juntos em sinergia, para que todos obtenham sucesso. Portanto, é importante incentivar os alunos a buscarem crescimento, a tentarem outra vez, e os professores a buscarem novas tecnologias e informações. Almeja-se uma escola que valorize as múltiplas competências e habilidades e que se aproxime das famílias na busca de fortalecer suas metas para o desenvolvimento saudável da cidadania das novas gerações. A mudança do termo fracasso escolar foi e continua a ser o desafio que este estudo propõe. Percebe-se, no entanto, que renomear o fracasso escolar não é tarefa fácil, pois implica em se opor ao desalento e transpor as dificuldades de associar sistemas com vistas a lembrar a todos a necessidade de perseverar.

\section{Referências}

Berg, L., Rostila, M., Saarela, J., \& Hjern, H. (2014). Parental death during childhood and subsequent school performance. Pediatrics, 133(4), 681-689.
Bastos, A., Fernandes, G. L., \& Passos, J. (2009). Analysis of school failure based on Portuguese micro data. Applied Economics Letters, 16, 1639-1643.

Braun, V. \& Clarke, V. (2006) Using thematic analysis in psychology. Qualitative Research in Psychology, 3(2), 77-101.

Costa, R. P. B., Lima, M. C. P., \& Pinheiro, C. V. Q. (2010). Os impasses da educação na adolescência contemporânea. Boletim de Psicologia, 10(132), 97-106.

Delors, J. (1998). Educação um tesouro a descobrir: Relatório para UNESCO da Comissão Internacional sobre Educação para o século XXI. Recuperado: 10 nov. 2015. Disponível: http://dhnet.org.br/dados/ relatorios/a_pdf/r_unesco_educ_tesouro_descobrir.pdf

Esteban, M. T. (2009). Avaliação e fracasso escolar: Questões para debate sobre a democratização da escola. Revista Lusófona de Educação, 13, 123-134. Recuperado: 11 nov. 2015. Disponível: http://www.redalyc. org/articulo.oa?id=34912395008

Ferraro, A. R. (2004). Escolarização no Brasil na ótica da exclusão. Em A. Marchesi \& C. H. Gil (Orgs.), Fracasso escolar: Uma perspectiva multicultural (E. Rosa, Trad., pp.48-65). Porto Alegre: Artmed.

Ferrera, J. M. C., López, C. M., \& Rodríguez, R. S. (2014).La repetición de curso y sus factores condicionantes en España. Revista de Educación, 365, 12-37.

Gauffin, K., Vinnerljung, B., Fridell, M., Hesse, M., \& Hjern, A. (2013). Childhood socio-economic status, school failure and drug abuse: A Swedish national cohort study. Addiction, 108(8), 1441-1449.

Gran, B. C. \& Nieto, M. A. P. (2013). El efecto del absentismo y el fracaso escolar en el consumo de tabaco, en una muestra de estudiantes de $3^{\circ}$ y $4^{\circ}$ de la educación secundaria obligatoria. Health and Addictions, 13(1), 53-58.Recuperado: 12 nov. 2015. Disponível: http://www. redalyc.org/pdf/839/83928046006.pdf

Guler, M. P. D. (2013). Success and failure in science education: a focus group study on Turkish students. Journal of Baltic Science Education, 12(6), 716-729.Recuperado: 10nov. 2015. Disponível: http://oaji.net/ articles/2015/987-1425811217.pdf

Hjörne, E. \& Säljö, R. (2014). Analysing and preventing school failure: Exploring the role of multi-professionality in pupil health team meetings. International Journal of Educational Research, 63, 5-14.

Instituto Nacional de Estudos e Pesquisas Educacionais Anísio Teixeira [INEP] (2012). Educacenso 2012 - Censo escolar. Recuperado: 10 nov. 2015. Disponível: http://www.linkatual.com/educacenso-2012.html

Ireland, V. E., Charlot, B., Gomes, C., Gusso, D., Carvalho, L., Fernandes, M., Ridha, E., \& Garcia, W. (2007). Repensando a escola: Um estudo sobre os desafios de aprender, ler e escrever. Brasília: UNESCO, MEC/INEP. 
Kamtsios, S. \& Karagiannopoulou, E. (2013). Conceptualizing students' academic hardiness dimensions: a qualitative study. European Journal Psychology Education, 28, 807-823. Kelly, D. H.\& Pink, W. T. (1982). School crime and individual responsibility: The perpetuation of amyth? The Urban Review, 14(1), 47-63

Lagana-Riordan, C., Aguilar, J., Franklin, C., Streeter, C. Kim, J. Tripodi, S., \& Hopson, L. (2011). At-risk students's perceptions of traditional schools and a solutions-focused public alternative school. Preventing School Failure, 55(3), 105-114.

Lima, F. R. (2014). Entrelace entre dificuldades de aprendizagem e produção do fracasso escolar: Algumas ponderações teórico-práticas. Psicologia. PT. Recuperado: 11 nov. 2015. Disponível: http://www. psicologia.pt/artigos/textos/A0784.pdf

Madalóz, R. J., Scalabrin, L. S., \& Jappe, M. (2012). O fracasso escolar sob o olhar docente: Alguns apontamentos. Trabalho apresentado em IX ANPEDSul:Seminário de PesquisaemEducaçãoda RegiãoSul, Caxias do Sul, RS: ANPED. Recuperado: 10 nov. 2015. Disponível: http://www. portalanpedsul.com.br/2012/home.php?link=grupos\&acao=listar_ trabalhos\&nome=GT04\%20-\%20Didática\&id=94

Marchesi, A. \& Pérez, E. M. (2004). A compreensão do fracasso escolar. Em A. Marchesi \& C. H. Gil (Orgs.), Fracasso escolar: Uma perspectiva multicultural (E. Rosa, Trad., pp.17-33). Porto Alegre: Artmed.

Martinelli, S. C. \& Genari, C. H. M. (2009). Relações entre desempenho escolar e orientações motivacionais. Estudos de Psicologia, 14(1), 1321. Recuperado: 13 nov. 2015. Disponível: http://www.scielo.br/pdf/ epsic/v14n1/a03v14n1.pdf

Millones, D., Leeuwen, K., \& Ghesquière, P. (2013). Associations between psychosocial functioning and academic achievement: The Peruvian case. Universitas Psychologica, 12 (3), 725-737.

Nocentini, A., Calamais, G., \& Menesini, E. (2012). Codevelopment of delinquent and depressive symptoms across adolescence: Time-invariant and time-varying effects of school and social failure. Journal of Clinical Child \& Adolescent Psychology, 41(6), 746-759. doi: 10.1080/15374416.2012.728155

Odd, D., Evans, D., \& Emond, A. (2013). Preterm birth, age at school entry and educational performance. Plos One, 8(10), 1- 6.

Organização das Nações Unidas para a Educação, Ciência e Cultura [UNESCO] (2014). Relatório do monitoramento global de EPT 2013/4 - Ensinar e aprender: Alcançar a qualidade para todos. Recuperado: 10 nov. 2015. Disponível: http://unesdoc.unesco.org/ images/0022/002256/225654POR.pdf

Osti, A. \& Brenelli, R. P. (2013a). Análise comparativa das relações entre ensino e aprendizagem por professores e alunos. Psicologia Escolar e Educacional, 17(1), 55-63. Recuperado: 13 nov. 2015. Disponível: http://www.scielo.br/pdf/pee/v17n1/a06v17n1.pdf
Osti, A. \& Brenelli, R. P. (2013b). Sentimentos de quem fracassa na escola: Análise das representações de alunos com dificuldades de aprendizagem. Psico-USF, 18(3), 417- 426.

Parecer CNE/CEB n. 11/2010 (2010, 7 de julho). Diretrizes Curriculares Nacionais para o Ensino Fundamental de 9 (nove) anos. Brasília, BR: CNE/CEB. Recuperado: 10 nov.2015. Disponível: http://portal.mec. gov.br/index.php?option=com_content\&id=12992:diretrizes-para-aeducacao-basica.

Patto, M. H. S. (2007). "Escolas cheias, cadeias vazias" nota sobre as raízes ideológicas do pensamento educacional brasileiro. Estudos Avançados, 21(61), 243-266.

Pezzi, F. A. S., Marin, A. H., \& Donelli, T. M. S. (2016). School Failure in the Perception of Adolescents, Parents and Teachers. Psico-USF, 21(2), 319-330.

Pezzi, F. A. S. \& Marin, A. H. (2016). Seguindo em frente? O fracasso escolar e as classes de aceleração. Psicologia Escolar e Educacional, 20(2), 219-227.

Robson, C. (1995). Real word research: A resource for scientist and practiotioner-researchs. Oxford: U.K.: Blackwell.

Rumberger, R. W. (2011). Dropping out: Why students drop out of high school and what canbe done about it. Cambridge: Harvard University Press. Recuperado: 10 out. 2015. Disponível: http://mina.education. ucsb.edu/rumberger/book/ch1.pdf

Silva, L. R. B. (2014). O currículo e a distorção idade-série nos anos iniciais do ensino fundamental. Dissertação de mestrado, Universidade de Brasilia, DF. Recuperado: 10 nov. 2015. Disponível: http://repositorio.unb. br/bitstream/10482/16776/1/2014_LedaReginaBitencourtdaSilva.pdf.

Soares, J. P., Aranha, A. M., \& Antunes, H. L. (2013). Relação entre os setores de prática desportiva, as modalidades desportivas e o aproveitamento escolar. Motricidade, 9(3), 3-11.

Soares, E. R. M. (2015). A distorção idade Série e a avaliação: Relações. Paper presentat the $37^{\mathrm{a}}$ reunião nacional da ANPED, Florianópolis-SC. Recuperado: 03 nov. 2015. Disponível: http://37reuniao.anped.org.br/ wp-content/uploads/2015/02/Trabalho-GT13-3571.pdf

Soponaru, C., Tincu, C., \& lorga, M. (2014).The influence of the sociometric status of students on academic achievement. Agathos: An International Review of the Humanities and Social Sciences, 5(2), 149-168. Recuperado: 10 out. 2015. Disponível: fromhttp://www.agathosinternational-review.com/issue5_2/17.Articol\%20-\%20CAMELIA\%20 SOPONARU.pdf

Williams, B. L., Dunlop, A. L., Kramer M., Dever, B. V., Hogue, C., \& Jain, L. (2013). Maternal factors perinatal origins of firstgrade academic failure: role of prematurity and maternal factors. Pediatrics, 131(4), 693-700. 
Recebido em: 01/04//2016

Aprovado em: 29/11/2016

\section{Sobre as autoras}

Magda Pozzobon Silva (magdapozzobon@hotmail.com)

Especialista em Psicologia Clínica (Terapia de casal e família e Terapia Cognitivo-comportamental) pelo Instituto da Família de Porto Alegre (2008 e 2010). Mestrado em Terapia Familiar Sistêmica pela Universidade Autônoma de Barcelona (2011), Mestrado em Psicologia pela Universidade do Vale do Rio dos Sinos, RS (2016).

Fénita Manuel Mahendra (fenita.mahendra@gmail.com)

Graduação em Psicologia pela Universidade Eduardo Mondlane, Moçambique (2010), Mestrado em Psicologia pela Universidade do Vale do Rio dos Sinos, Brasil (2015)

Angela Helena Marin (ahmarin@hotmail.com)

Especialista em Psicologia Clínica (Terapia de casal e família) pelo Instituto da Família de Porto Alegre (2008). Mestrado e Doutorado em Psicologia pela Universidade Federal do Rio Grande do Sul, (2009), Professora e pesquisadora no Programa de Pós-graduação em Psicologia Clínica da Universidade do Vale do Rio dos Sinos, RS. 